\title{
Comparison of Pain Perception between Clear Aligners and Fixed Appliances: A Systematic Review and Meta-Analysis
}

\author{
Dinis Pereira $^{1,2}$, Vanessa Machado ${ }^{1,2, * \mathbb{C}}$, João Botelho ${ }^{2}\left(\mathbb{D}\right.$, Luís Proença ${ }^{3} \mathbb{C}^{\text {, }}$ \\ José João Mendes 2 (1) and Ana Sintra Delgado ${ }^{1,2}$ \\ 1 Orthodontics Department, CRU, CiiEM, Egas Moniz-Cooperativa de Ensino Superior, 2829-511 Almada, \\ Portugal; adtper@gmail.com (D.P.); anasintradelgado@gmail.com (A.S.D.) \\ 2 Clinical Research Unit (CRU), Centro de Investigação Interdisciplinar Egas Moniz (CiiEM), \\ Instituto Universitário Egas Moniz, 2829-511 Almada, Portugal; jbotelho@egasmoniz.edu.pt (J.B.); \\ jmendes@egasmoniz.edu.pt (J.J.M.) \\ 3 Quantitative Methods for Health Research Unit (MQIS), CiiEM, Egas Moniz-Cooperativa de Ensino \\ Superior, 2829-511 Almada, Portugal; lproenca@egasmoniz.edu.pt \\ * Correspondence: vmachado@egasmoniz.edu.pt
}

Received: 23 May 2020; Accepted: 19 June 2020; Published: 22 June 2020

Featured Application: Clear aligners are associated with significantly less pain than fixed appliances during the first seven days of orthodontic treatment.

\begin{abstract}
We aimed to compare the pain discomfort levels between clear aligners and fixed appliances at multiple time points. Four electronic databases (Pubmed, Medline, CENTRAL and Scholar) were searched up to May 2020. There were no year or language restrictions. Randomized clinical trials and case-control studies comparing pain perception through pain visual analog scale (VAS) in patients treated with clear aligners and with fixed appliances were included. Risk of bias within and across studies was assessed using Cochrane tool and Newcastle-Ottawa Scale (NOS) approach. Random-effects meta-analysis were conducted. VAS score and analgesic consumption were collected. Random-effects meta-analyses were used to synthesize available data. Following the review protocol, five articles met the inclusion criteria and were included, with a total of 273 participants ( 177 females, 96 males). Overall, clear aligners were associated with significantly less pain than fixed appliances during the first seven days of orthodontic treatment. Patients treated with clear aligners experience less pain discomfort than those treated with fixed appliances and consume less analgesics, with SORT A recommendation.
\end{abstract}

Keywords: clear aligners; fixed appliances; pain perception; VAS (visual analog scale) scale; systematic review; meta-analysis

\section{Introduction}

With the increase of esthetic requirements, facial's micro and macro-esthetic and smile have become a priority for adolescents and adults [1,2]. Consequently, patients lean to more esthetic and comfortable orthodontic treatments [3].

In 1945, Kesling introduced the concept of clear aligners, that aimed to stress minor tooth movement, usually at the end of orthodontic treatment or to treat minor alignment relapse [4]. Since 1998, clear aligners have become popular and quickly the preferred orthodontic appliances for patients with high esthetic demands [5,6]. In addition, mechanical tooth movement is associated with 
cognitive, affective and behavioral responses [7] and periodontal mechanoreceptors and chewing muscles (as source of pain receptors) also contribute to pain experience [8,9].

Clear aligners are esthetically more appealing than fixed appliances with brackets and wires [1] and patients benefit by being able to have full access to remove clear aligners to eat and for oral hygiene. Still, patients treated with clear aligners have better periodontal health than those with fixed appliances, and they promote better compliance with oral hygiene in teenagers [10-12].

Moreover, pain experience after initial archwire placement in fixed appliances is well established, comparing multistrand stainless steel and superelastic NiTi archwires [13-20]. However, the difference in the pain perception of clear aligners compared with fixed appliances remains unclear. A recent systematic review concluded that orthodontic patients treated with Invisalign appear to feel lower levels of pain than those treated with fixed appliances during the first few days of treatment, however they were not able to synthetize the magnitude of this difference [21].

Patients choose clear aligners in hope that these appliances will have low impact on their quality of life [22]. Therefore, it becomes relevant to evaluate whether there is a difference in pain perception between fixed appliances and clear aligners. In this sense, we may contribute to a more grounded decision by the patient and the clinician.

Our main objective in this systematic review was to compare the discomfort levels between clear aligners and fixed appliances. Second, we analyzed analgesic consumption difference between the aforementioned orthodontic appliances. The review PICO research question is "Do clear aligners have less pain discomfort impact than fixed appliances treatment in orthodontic patients?", with the following statements: orthodontic patients (patients-P); clear aligners (intervention/exposure- $\mathrm{I}$ ); fixed appliances (comparison-C); pain discomfort (outcome-O). Our null hypothesis was that clear aligners cause similar pain perception than conventional fixed appliances.

\section{Materials and Methods}

\subsection{Subsection}

The present systematic review was conducted and reported according to the preferred reporting items for systematic reviews and meta-analyses (PRISMA) guidelines for reporting studies that evaluate health care interventions [23] (in detail in Supplementary Table S1) and its extension for abstracts [24]. The protocol was previously defined and has been registered in the International Prospective Register of Systematic Reviews (PROSPERO; CRD42019124534).

\subsection{Eligibility Criteria}

Studies were eligible for inclusion based on the following criteria:

1 Clear aligners treatment comparing with fixed appliances and determined pain discomfort through pain visual analog scale (VAS) at multiple time points;

2 Randomized and non-randomized studies;

3 Studies in humans.

The exclusion criteria were:

1 Studies reporting results emerging from questionnaires;

2 Studies lacking control;

3 Retrospective studies;

4 In vitro and animal studies;

5 Case reports/case series;

6 Editorials, opinions, narrative reviews and technique description articles, without reported sample. 


\subsection{Search Strategy}

A total of four electronic databases (Pubmed, Medline, CENTRAL and Google Scholar) were searched systematically until May 2020. The strategy used for the electronic search was the following: (VAS OR visual analog scale OR VAS scale OR pain perception OR pain) AND (Invisalign OR Invisalign aligner OR clear aligner) AND (orthodontic brackets OR bracket OR fixed appliance). The reference lists of included articles and relevant reviews were manually searched. Gray literature was searched using the latter strategy in OpenGray (www.opengrey.eu).

\subsection{Assessment of Validity}

The eligibility of each study was assessed independently by two investigators (VM and DP), who screened the titles and/or abstracts of retrieved studies. Inclusion was dependent on the following eligibility criteria: randomized clinical trials and case-control studies who compare the discomfort level produced by fixed appliances and clear aligners at multiple time points. Final selection of studies was performed by three authors independently (VM, DP, JB) and verified by a fourth and fifth author (JJM, ASD), by reviewing the full text based on inclusion criteria above. Discussion resolved any disagreements. Non-full papers, such as conference abstracts, thesis and letters to editors, were excluded.

\subsection{Data Extraction}

Characteristics of the included studies and numerical data were extracted in duplicate by two authors (VM and DP) onto a predefined data extraction table: citation, publication status and year of publication, study design, setting, number of cases and characteristics of the participants (mean age, sex), VAS scores at multiple time points, type of fixed appliances and analgesic consumption. Final data were reviewed by a third author (JB).

\subsection{Risk of Bias of Included Studies}

Risk of bias (RoB) was performed by two independent reviewers (VM and JB). In areas of disagreements, a collective decision was obtained after a discussion between all authors to approach a consensus, with an opinion of a third reviewer (DP). RoB of RCTs was assessed with the Cochrane RoB2 tool [25]. Case-control and cohort studies were appraised with the Newcastle-Ottawa scale. "Stars" (points) were attributed for each methodologic quality criterion and each study could achieve a maximum of 8 points. Studies with 7 to 8 points ( $80 \%$ or more of the domains satisfactorily fulfilled) were arbitrarily considered to be of low RoB, studies with 5 to 6 stars were of medium RoB and studies with less than 5 stars were of high RoB. Disagreements between the review authors over the risk of bias in particular studies were resolved by discussion, with the involvement of a third review author (DP) where necessary.

\subsection{Summary Measures \& Synthesis of Results}

For the conversion of median and interquartile range VAS score values to mean and standard deviations, Hozo et al. [26] procedure was used, under the assumption of normal distribution. All statistical analyses were performed in R version 3.4.1 (R Studio Team 2018, Boston, MA, USA) using a DerSimonian-Laird random-effects model [27]. All random-effects meta-analysis and forest plots were performed using 'meta' package [28].

First, pain discomfort through VAS score of clear aligners versus fixed appliances was appraised through DerSimonian-Laird (DS) random-effect analysis. Of the included studies, the percentage of analgesic consumption was also carried out, through binary random-effects analysis. Quantity $\mathrm{I}^{2}$ was used to measure to account for homogeneity and calculated through the $\chi 2$ test. Publication bias analysis was planned to be performed if, at least, we had 10 or more studies included [29]. All tests are 
two-tailed with alpha set at 0.05 , except for the homogeneity test whose significance level cutoff will consider to be 0.10 due to the low power of the $\chi 2$ test with a limited amount of studies.

\subsection{Strength of Recommendation}

The SORT (strength of recommendation taxonomy) was used to judge the strength and quality of the evidence [30]. We discussed the outcomes of the present systematic review, clinical recommendations and future necessary research.

\section{Results}

\subsection{Study Selection}

From the databases and other sources, the initial search resulted in a total of 98 record, resulting in 58 after duplicates removal. Following title and abstract screening, 23 studies were selected for full-text evaluation. Nevertheless, after full-text eligibility assessment, 18 studies were excluded (in detail in Supplementary Table S2). Therefore, the meta-analysis was performed on the basis of 5 articles. The flow chart of study selection together with reasons for exclusion is provided in Figure 1.

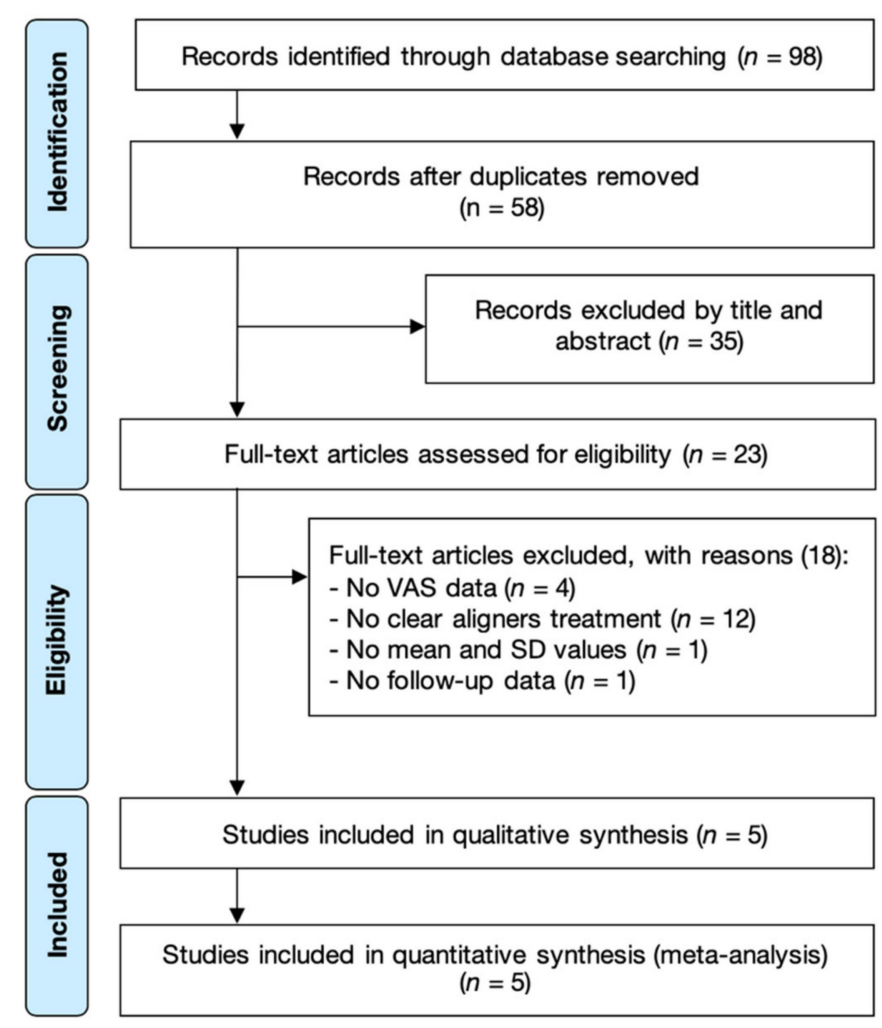

Figure 1. PRISMA (preferred reporting items for systematic reviews and meta-analyses) flowchart.

\subsection{Study Characteristics}

Three prospective studies evaluated the pain discomfort of clear aligners through the comparison with fixed appliances. A total of 273 participants (177 females, 96 males) were included. The characteristic of the participants is shown in Table 1. 
Table 1. Included studies characteristics.

\begin{tabular}{|c|c|c|c|c|c|c|}
\hline \multirow{2}{*}{ Study } & \multirow{2}{*}{ Country } & \multirow{2}{*}{ N (F/M) } & \multicolumn{2}{|c|}{ Participants } & \multirow[t]{2}{*}{ Outcome } & \multirow{2}{*}{ Funding } \\
\hline & & & CA & FA & & \\
\hline Miller (2007) [31] & USA & $60(43 / 17)$ & 33 & 27 & $\begin{array}{l}\text { Adults treated with Invisalign } \\
\text { aligners experienced less pain } \\
\text { and fewer negative impacts on } \\
\text { their lives during the first week } \\
\text { of orthodontic treatment than } \\
\text { did those treated with } \\
\text { fixed appliances }\end{array}$ & NR \\
\hline Shalish (2012) [32] & USA & $68(45 / 23)$ & 21 & 47 & $\begin{array}{l}\text { The Invisalign patients } \\
\text { complained of relatively high } \\
\text { levels of pain in the first days } \\
\text { after insertion; however this } \\
\text { group was characterized by the } \\
\text { lowest level of oral symptoms } \\
\text { and by a similar level of } \\
\text { general activity disturbances } \\
\text { and oral dysfunction compared } \\
\text { to the Buccal appliance. }\end{array}$ & NR \\
\hline White (2017) [6] & USA & $41(24 / 17)$ & 23 & 18 & $\begin{array}{l}\text { Patients treated with traditional } \\
\text { fixed appliances reported } \\
\text { greater discomfort and } \\
\text { consumed more analgesics than } \\
\text { patients treated with aligners. }\end{array}$ & $\begin{array}{l}\text { Partially funded by } \\
\text { the Robert E. Gaylord } \\
\text { Endowed Chair in } \\
\text { Orthodontics and by } \\
\text { Align Technology }\end{array}$ \\
\hline Almasoud (2018) [33] & Saudi Arabia & $64(42 / 22)$ & 32 & 32 & $\begin{array}{l}\text { During the first week of } \\
\text { orthodontic treatment, patients } \\
\text { treated with Invisalign aligners } \\
\text { reported lower pain than did } \\
\text { those treated with passive } \\
\text { self-ligating fixed appliances. }\end{array}$ & NR \\
\hline Piergentili (2019) [34] & Italy & $40(23 / 17)$ & 20 & 20 & $\begin{array}{l}\text { Therapy with traditional fixed } \\
\text { orthodontics appliances caused } \\
\text { more discomfort to the patients, } \\
\text { than clear aligner therapy }\end{array}$ & NR \\
\hline
\end{tabular}

CA—clear aligners; FA—fixed appliances; USA—United States of America; NR—not reported.

\subsection{Risk of Bias within Studies}

One RCT was included and was assessed as having some concerns of risk of bias [6] (Figure 2). Table 2 (NOS scale scores) shows the risk of bias assessment for the included studies and all four studies were considered of low risk of bias [31-34].

\begin{tabular}{|c|c|c|c|c|c|c|}
\hline \multirow{2}{*}{ White et al. 2017} & R & D & Mi & Me & S & O \\
\hline & + & + & + & + & $?$ \\
\hline
\end{tabular}

Figure 2. RoB2 assessment. R-bias arising from the randomization process; D—bias due to deviations from intended interventions; $\mathrm{Mi}$ - bias due to missing outcome data; $\mathrm{Me}$ - bias in measurement of the outcome; $\mathrm{S}-$ bias in selection of the reported result; $\mathrm{O}$ - overall risk of bias.

Table 2. NOS (Newcastle-Ottawa Scale) score for case-control studies.

\begin{tabular}{ccccccccccc}
\hline & \multicolumn{3}{c}{ Selection } & & Comparability & \multicolumn{3}{c}{ Outcome } & \multirow{2}{*}{ TOTAL } & \multirow{2}{*}{ Score } \\
\hline & $\mathbf{1}$ & $\mathbf{2}$ & $\mathbf{3}$ & $\mathbf{4}$ & $\mathbf{5}$ & $\mathbf{6}$ & $\mathbf{7}$ & $\mathbf{8}$ & & Low \\
Miller (2007) [31] & $\mathrm{a}$ & $\mathrm{a}$ & $\mathrm{a}$ & $\mathrm{a}$ & $\mathrm{a}$ & $\mathrm{a}$ & $\mathrm{a}$ & $\mathrm{a}$ & 8 & Low \\
Shalish (2012) [32] & $\mathrm{a}$ & $\mathrm{a}$ & $\mathrm{a}$ & $\mathrm{a}$ & $\mathrm{a}$ & $\mathrm{a}$ & $\mathrm{a}$ & $\mathrm{a}$ & 8 & Low \\
Almasoud (2018) [33] & $\mathrm{c}$ & $\mathrm{a}$ & $\mathrm{a}$ & $\mathrm{a}$ & $\mathrm{a}$ & $\mathrm{a}$ & $\mathrm{a}$ & $\mathrm{a}$ & 7 & Low \\
Piergentili (2019) [34] & $\mathrm{a}$ & $\mathrm{a}$ & $\mathrm{a}$ & $\mathrm{a}$ & $\mathrm{a}$ & $\mathrm{a}$ & $\mathrm{a}$ & $\mathrm{a}$ & 8 & L
\end{tabular}

1-case definition adequacy; 2-representativeness of the cases; 3-selection of controls; 4-definition of controls; 5-comparability of cohorts on the basis of the design or analysis; 6-ascertainment of outcome; 7-save method of ascertainment for cases and controls; 8-nonresponse rate. 


\subsection{Synthesis of Results}

Data from three studies including 273 patients reported pain discomfort through VAS score of clear aligners versus fixed appliances [6,31-34]. Four studies provided data on a daily basis $[6,31,32,34]$, while one had data for pain discomfort at day 1, 3 and 7 after [33].

Clear aligners promote lower pain experience than patients using fixed appliances, and the difference is statistically significant for 1, 3, 6 and 7 days of follow-up (Table 3). The overall pain experience also favored clear aligners. Funnel plot analysis revealed no publication bias (Figure 3).

Table 3. Subgroup meta-analysis of VAS score from 1 to 7 days of follow-up.

\begin{tabular}{|c|c|c|c|c|c|c|c|}
\hline Subgroup Meta-Analysis & $\mathbf{n}$ & MD & $95 \% \mathrm{CI}$ & $p$-Value & $I^{2}(\%)$ & Tau & $p$-Value \\
\hline Day 1 & 6 & 1.07 & $(0.00 ; 2.13)$ & $<0.001$ & 84.9 & 1.16 & $<0.001$ \\
\hline Day 2 & 5 & 0.60 & $(-0.20 ; 1.41)$ & $>0.05$ & 80.7 & 0.77 & $<0.001$ \\
\hline Day 3 & 6 & 1.25 & $(0.32 ; 2.17)$ & $<0.001$ & 83.0 & 0.99 & $<0.001$ \\
\hline Day 4 & 5 & 0.79 & $(-0.07 ; 1.65)$ & $>0.05$ & 83.8 & 0.84 & $<0.001$ \\
\hline Day 5 & 5 & 0.62 & $(-0.13 ; 1.37)$ & $>0.05$ & 83.7 & 0.71 & $<0.001$ \\
\hline Day 6 & 5 & 0.76 & $(0.31 ; 1.21)$ & $<0.001$ & 67.6 & 0.38 & $<0.001$ \\
\hline Day 7 & 6 & 0.79 & $(0.37 ; 1.22)$ & $<0.001$ & 64.2 & 0.36 & $<0.001$ \\
\hline Overall & 6 & 0.33 & $(0.45 ; 1.57)$ & $<0.001$ & 80.5 & 0.58 & $<0.001$ \\
\hline
\end{tabular}

Test for subgroup differences (random effects model): $\mathrm{Q}=1.62, p=0.9514$. MD-Mean Difference.

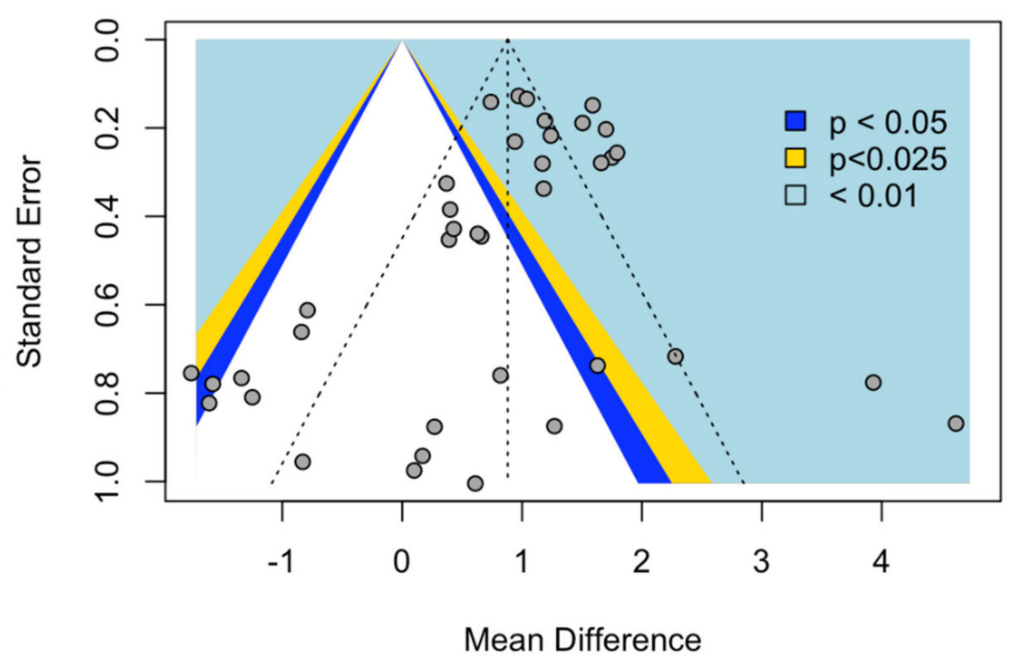

Figure 3. Funnel plot. The outer dashed lines indicate the triangular region within which $95 \%$ of studies are expected to lie in the absence of both biases and heterogeneity (fixed effect summary log odds ratio $\pm 1.96 \times$ standard error of summary log odds ratio). The dashed vertical line corresponds to no intervention effect. The distribution gives a clear visual impression of symmetry, which is confirmed by a $p>0.05$.

A detailed number of analgesic consumption at day 1, 3 and 7 after, were reported in three studies $[6,31,33]$. Overall, patients treated with clear aligners have significantly less analgesic consumption compared with fixed appliances group control, one day and seven days after treatment beginning (Table 4). Overall, patients with fixed appliances consume more analgesics at the beginning of treatment. 
Table 4. Subgroup meta-analysis of Analgesic consumption at 1, 3 and 7 days of follow-up.

\begin{tabular}{cccccccc}
\hline Subgroup Meta-Analysis & $\mathrm{n}$ & OR & $95 \% \mathrm{CI}$ & $p$-Value & $\mathrm{I}^{\mathbf{2}}(\%)$ & Tau & $p$-Value \\
\hline Day 1 & 3 & 0.15 & $(0.04 ; 0.50)$ & $<0.001$ & 84.9 & 49.3 & 0.14 \\
\hline Day 3 & 3 & 0.75 & $(0.11 ; 5.10)$ & $<0.001$ & 83.0 & 81.0 & $<0.001$ \\
\hline Day 7 & 3 & 0.23 & $(0.52 ; 0.99)$ & $<0.001$ & 64.2 & 0.0 & 0.79 \\
\hline Overall & 3 & 0.30 & $(0.12 ; 0.72)$ & $<0.001$ & 80.5 & 58.8 & 0.01 \\
\hline
\end{tabular}

Test for subgroup differences (random effects model): $\mathrm{Q}=1.97, p=0.3734$. OR-Odds Ratio.

\subsection{Synthesis of Results}

According to the SORT recommendation, the evidence revealed that clear aligners produce less pain experience than fixed appliances, based on consistent findings of at least two good-quality meta-analyses that obtained significant results (SORT A) [30].

\section{Discussion}

\subsection{Summary of Main Findings}

This systematic review demonstrate that clear aligners are significantly associated with less pain rather than fixed appliances during the first week of orthodontic treatment, with an overall SORT A recommendation. Clear aligners patients present less risk of analgesics consumption compared to patients with fixed appliances and present significant differences.

\subsection{Quality of the Evidence, Limitations and Potential Biases in the Review Process}

The strengths of this systematic review include the extensive unrestrictive literature search, with a rigorous and predetermined protocol implemented in each phase. However, there are limitations worth to mention among the included studies.

The included investigations were of small samples, and one of them lack sample size calculation [31]. As well, there are a diversity of fixed appliances description since one did not refer the type of buccal fixed appliances [31], one used self-ligated fixed appliance [33], three used a twin-bracket fixed appliance [6], and one also had lingual brackets [32,34]. Though passive self-ligating systems result in minor periodontal ligament ischemia and therefore less discomfort [35], literature evidences that pain experience in the beginning of treatment is independent of bracket type [36-38]. The type and size of archwires were described in four studies [6], though they differed in type and size among them, which is also a limitation worth mentioning. Nevertheless, previous studies have found no significant differences in the pain perception using different archwires types $[36,39,40]$. Furthermore, Piergentilli et al. [33] have placed the fixed appliance exclusively in the maxillary arch during the first week of treatment, and this may explain also the observed heterogeneity.

Moreover, only one study [6] performed random selection, while the remaining four [31-34] did not randomly assigned the treatment modalities due to their cohort design nature. However, randomizing adult patients is not simple, since some of whom are unwilling or unable to comply with the random assignment due to esthetic reasons [32]. This difficulty limits the ability to completely randomize the study. The fact that the patient has a choice demonstrates personality traits, which can impair the perception of pain. Notwithstanding, the RCT included in this review [33] lacked allocation concealment contributing to the overall concern on the risk of bias [33]. Allocation concealment is predictably difficult to achieve in this type of studies in which the intervention is a removable appliance and its control a fixed appliance.

Additionally, pain experience is a notoriously subjective response and there is a nonlinear relationship upon multiple factors such as age, gender, individual pain threshold, the magnitude of the force applied, present emotional state and stress, cultural differences and previous pain experiences $[14,17,19,41-44]$. A hypothetical limitation would be the fact that there is an unbalanced 
gender ratio. However, gender has no significant effect on orthodontic pain perception $[14,17,19,45]$, except in adolescents, where females have less pain tolerance than males [46,47].

Finally, placing attachments at the beginning of the clear aligner treatment is relevant for pain perception because they cause more pressure during the insertion of the aligner. Among the included studies, Miller et al. [31] did not place attachments, two studies used attachments since they placed the first aligners [6] and Almasoud [33] delayed the attachments placement until the third set of aligners. Despite Shalish et al. [33] did not refer the placement of attachments, patients with clear aligners reported more pain than those using buccal fixed appliances, and alike those using lingual fixed appliances patients. The reason to this pain experience difference could be a greater mechanical force caused by the attachment placement, though they should be investigated deeply in the future. In addition, the importance of the periodontal mechanoreceptors and chewing muscles during clear aligners tooth movement is a matter to be further investigated.

\section{Conclusions}

Within the limitations of this systematic review, the results show that patients treated with clear aligners experience less pain and discomfort than patients treated with fixed appliances. This information may clarify patients about what to expect during the beginning of orthodontic treatment. In the future, larger randomized clinical trials are needed to demonstrate unequivocally that clear aligners are more comfortable than fixed appliances throughout orthodontics treatment.

\section{Implications for Clinical Practice and Research}

These findings may help both patients and clinicians in the treatment modality decision, concerning pain parameters and analgesic consultation, in the first phase of orthodontic treatment.

In the main, randomized clinical trials are needed to perform a robust comparison of clear aligners and buccal fixed appliances. Aspects concerning long-term outcomes appraisal, objective measurements of patient-centered reported outcomes (such as quality of life) and adverse effects (including allergies, periodontal damages and functional impairment) are important factors to consider.

Additionally, the present review encompassed mainly Invisalign ${ }^{\circledR}$ aligners. Future research should be conducted in different clear aligners systems, to find out if exists significant differences between different types of clear aligners systems in pain perception and analgesic drugs intake.

Supplementary Materials: The following are available online at http://www.mdpi.com/2076-3417/10/12/4276/s1, Table S1: PRISMA Checklist, Table S2: List of potentially relevant studies not included in the systematic review, along with the reasons for exclusion.

Author Contributions: Conceptualization, D.P., V.M., J.B., L.P., J.J.M., A.S.D.; methodology, V.M. and J.B.; software, V.M. and J.B.; validation D.P., V.M. and J.B.; formal analysis, J.B.; data curation, D.P., V.M. and J.B. All authors have read and agreed to the published version of the manuscript.

Funding: This research received no external funding.

Conflicts of Interest: The authors declare no conflict of interest.

\section{References}

1. Ziuchkovski, J.P.; Fields, H.W.; Johnston, W.M.; Lindsey, D.T. Assessment of perceived orthodontic appliance attractiveness. Am. J. Orthod. Dentofac. Orthop. 2008, 133, 68-78. [CrossRef] [PubMed]

2. Sarver, D.M. Interactions of hard tissues, soft tissues, and growth over time, and their impact on orthodontic diagnosis and treatment planning. Am. J. Orthod. Dentofac. Orthop. 2015, 148, 380-386. [CrossRef]

3. Rosvall, M.D.; Fields, H.W.; Ziuchkovski, J.; Rosenstiel, S.F.; Johnston, W.M. Attractiveness, acceptability, and value of orthodontic appliances. Am. J. Orthod. Dentofac. Orthop. 2009, 135, e1-e276. [CrossRef]

4. Kesling, H.D. The philosophy of the tooth positioning appliance. Am. J. Orthod. Oral Surg. 1945, 31, $297-304$. [CrossRef]

5. Wong, B.H.; Scholz, R.P.; Turpin, D.L. Invisalign A to Z. Am. J. Orthod. Dentofac. Orthop. 2002, 121, 540-541. [CrossRef] 
6. White, D.W.; Julien, K.C.; Jacob, H.; Campbell, P.M.; Buschang, P.H. Discomfort associated with Invisalign and traditional brackets: A randomized, prospective trial. Angle Orthod. 2017, 87, 801-808. [CrossRef]

7. Giddon, D.B.; Anderson, N.K.; Will, L.A. Cognitive, Affective, and Behavioral Responses Associated with Mechanical Tooth Movement. Semin. Orthod. 2007, 13, 212-219. [CrossRef]

8. Piancino, M.G.; Isola, G.; Cannavale, R.; Cutroneo, G.; Vermiglio, G.; Bracco, P.; Anastasi, G.P. From periodontal mechanoreceptors to chewing motor control: A systematic review. Arch. Oral Biol. 2017, 78, 109-121. [CrossRef]

9. Isola, G.; Anastasi, G.P.; Matarese, G.; Williams, R.C.; Cutroneo, G.; Bracco, P.; Piancino, M.G. Functional and molecular outcomes of the human masticatory muscles. Oral Dis. 2018, 24, 1428-1441. [CrossRef]

10. Abbate, G.M.; Caria, M.P.; Montanari, P.; Mannu, C.; Orrù, G.; Caprioglio, A.; Levrini, L. Parodontale Gesundheit von Teenagern mit herausnehmbaren Alignern und festsitzenden kieferorthopädischen Apparaturen. J. Orofac. Orthop. 2015, 76, 240-250. [CrossRef]

11. Azaripour, A.; Weusmann, J.; Mahmoodi, B.; Peppas, D.; Gerhold-Ay, A.; Van Noorden, C.J.F.; Willershausen, B. Braces versus Invisalign $®$ : Gingival parameters and patients' satisfaction during treatment: A cross-sectional study. BMC Oral Health 2015, 15, 1-5. [CrossRef] [PubMed]

12. Lu, H.; Tang, H.; Zhou, T.; Kang, N. Assessment of the periodontal health status in patients undergoing orthodontic treatment with fixed appliances and Invisalign system. Medicine 2018, 97, e0248. [CrossRef] [PubMed]

13. Wang, Y.; Liu, C.; Jian, F.; Mcintyre, G.T.; Millett, D.T.; Hickman, J.; Lai, W. Initial arch wires used in orthodontic treatment with fixed appliances. Cochrane Database Syst. Rev. 2018, 7. [CrossRef] [PubMed]

14. Wilson, S.; Ngan, P.; Kess, B. Time course of the discomfort in young patients undergoing orthodontic treatment. Pediatr. Dent. 1989, 11, 107-110. [PubMed]

15. Jones, M.; Chan, C. The pain and discomfort experienced during orthodntic treatment: A randomized controlled clinical trial of two intial aligning arch wires. Am. J. Orthod. Dentofac. Orthop. 1992, 102, 373-381. [CrossRef]

16. Ngan, P.; Kess, B.; Wilson, S. Perception of discomfort by patients undergoing orthodontic treatment. Am. J. Orthod. Dentofac. Orthop. 1989, 96, 47-53. [CrossRef]

17. Scheurer, P.A.; Firestone, A.R.; Bürgin, W.B. Perception of pain as a result of orthodontic treatment with fixed appliances. Eur. J. Orthod. 1996, 18, 349-357. [CrossRef]

18. Stewart, F.N.; Kerr, W.J.S.; Taylor, P.J.S. Appliance wear: The patient's point of view. Eur. J. Orthod. 1997, 19, 377-382. [CrossRef]

19. Krishnan, V.; Davidovitch, Z. Cellular, molecular, and tissue-level reactions to orthodontic force. Am. J. Orthod. Dentofac. Orthop. 2006, 129, e1-e469. [CrossRef]

20. Grieve, W.G.; Johnson, G.K.; Moore, R.N.; Reinhardt, R.A.; DuBois, L.M. Prostaglandin E (PGE) and interleukin-1 $\beta$ (IL-1 $\beta$ ) levels in gingival crevicular fluid during human orthodontic tooth movement. Am. J. Orthod. Dentofac. Orthop. 1994, 105, 369-374. [CrossRef]

21. Cardoso, P.C.; Espinosa, D.G.; Mecenas, P.; Flores-Mir, C.; Normando, D. Pain level between clear aligners and fixed appliances: A systematic review. Prog. Orthod. 2020, 21, 3. [CrossRef]

22. Flores-Mir, C.; Brandelli, J.; Pacheco-Pereira, C. Patient satisfaction and quality of life status after 2 treatment modalities: Invisalign and conventional fixed appliances. Am. J. Orthod. Dentofac. Orthop. 2018, 154, 639-644. [CrossRef] [PubMed]

23. Liberati, A.; Altman, D.G.; Tetzlaff, J.; Mulrow, C.; Gøtzsche, P.C.; Ioannidis, J.P.A.; Clarke, M.; Devereaux, P.J.; Kleijnen, J.; Moher, D. The PRISMA statement for reporting systematic reviews and meta-analyses of studies that evaluate health care interventions: Explanation and elaboration. PLoS Med. 2009, 6, e1000100. [CrossRef] [PubMed]

24. Beller, E.M.; Glasziou, P.P.; Altman, D.G.; Hopewell, S.; Bastian, H.; Chalmers, I.; Gøtzsche, P.C.; Lasserson, T.; Tovey, D. PRISMA for Abstracts: Reporting Systematic Reviews in Journal and Conference Abstracts. PLoS Med. 2013, 10, e1001419. [CrossRef]

25. Sterne, J.A.C.; Savović, J.; Page, M.J.; Elbers, R.G.; Blencowe, N.S.; Boutron, I.; Cates, C.J.; Cheng, H.Y.; Corbett, M.S.; Eldridge, S.M.; et al. RoB 2: A revised tool for assessing risk of bias in randomised trials. BMJ 2019, 366, 1-8. [CrossRef] [PubMed]

26. Hozo, S.P.; Djulbegovic, B.; Hozo, I. Estimating the mean and variance from the median, range, and the size of a sample. BMC Med. Res. Methodol. 2005, 5, 1-10. [CrossRef] 
27. Schwarzer, G.; Carpenter, J.R.; Rücker, G. Meta-Analysis with R; Springer: Berlin/Heidelberg, Germany, 2015, ISBN 9783319214153.

28. Schwarzer, G. Meta: An R Package for Meta-Analysis. R News 2007, 7, 40-45.

29. Higgins, J.; Green, S. Cochrane Handbook for Systematic Reviews of Interventions; 5.1.0 (updated March 2011); The Cochrane Collaboration: 2011. Available online: https://www.cochrane-handbook.org (accessed on 15 April 2020).

30. Newman, M.G.; Weyant, R.; Hujoel, P. JEBDP Improves Grading System and Adopts Strength of Recommendation Taxonomy Grading (SORT) for Guidelines and Systematic Reviews. J. Evid. Based. Dent. Pract. 2007, 7, 147-150. [CrossRef]

31. Miller, K.B.; McGorray, S.P.; Womack, R.; Quintero, J.C.; Perelmuter, M.; Gibson, J.; Dolan, T.A.; Wheeler, T.T. A comparison of treatment impacts between Invisalign aligner and fixed appliance therapy during the first week of treatment. Am. J. Orthod. Dentofac. Orthop. 2007, 131, e1-e302. [CrossRef]

32. Shalish, M.; Cooper-Kazaz, R.; Ivgi, I.; Canetti, L.; Tsur, B.; Bachar, E.; Chaushu, S. Adult patients' adjustability to orthodontic appliances. Part I: A comparison between Labial, Lingual, and Invisalign ${ }^{\mathrm{TM}}$. Eur. J. Orthod. 2012, 34, 724-730. [CrossRef]

33. Almasoud, N.N. Pain perception among patients treated with passive self-ligating fixed appliances and invisalign®aligners during the first week of orthodontic treatment. Korean J. Orthod. 2018, 48, 326-332. [CrossRef] [PubMed]

34. Piergentili, M.; Bucci, R.; Madariaga, A.C.P.; Martina, S.; Rongo, R.; D'Antò, V. Pain and discomfort associated with labial multibracket appliances vs clear aligners. J. Aligner Orthod. 2019, 3, 205-212.

35. Wright, N.; Modarai, F.; Cobourne, M.T.; DiBiase, A.T. Do you do Damon $®$ ? What is the current evidence base underlying the philosophy of this appliance system? J. Orthod. 2011, 38, 222-230. [CrossRef] [PubMed]

36. Fleming, P.S.; DiBiase, A.T.; Sarri, G.; Lee, R.T. Pain experience during initial alignment with a self-ligating and a conventional fixed orthodontic appliance system. Angle Orthod. 2009, 79, 46-50. [CrossRef]

37. Fleming, P.S.; Johal, A. Self-ligating brackets in orthodontics a systematic review. Angle Orthod. 2010, 80, 575-584. [CrossRef] [PubMed]

38. Miles, P.G.; Weyant, R.J.; Rustveld, L. A clinical trial of damon $2^{\mathrm{TM}}$ Vs conventional twin brackets during initial alignment. Angle Orthod. 2006, 76, 480-485.

39. Rahman, S.; Spencer, R.J.; Littlewood, S.J.; O’Dywer, L.; Barber, S.K.; Russell, J.S. A multicenter randomized controlled trial to compare a self-ligating bracket with a conventional bracket in a UK population: Part 2: Pain perception. Angle Orthod. 2016, 86, 149-156. [CrossRef]

40. Scott, P.; Sherriff, M.; DiBiase, A.T.; Cobourne, M.T. Perception of discomfort during initial orthodontic tooth alignment using a self-ligating or conventional bracket system: A randomized clinical trial. Eur. J. Orthod. 2008, 30, 227-232. [CrossRef]

41. Bergius, M.; Kiliaridis, S.; Berggren, U. Pain in orthodontics. A review and discussion of the literature. J. Orofac. Orthop. 2000, 61, 125-137. [CrossRef]

42. Firestone, A.R.; Scheurer, P.A.; Bürgin, W.B. Patients' anticipation of pain and pain-related side effects, and their perception of pain as a result of orthodontic treatment with fixed appliances. Eur. J. Orthod. 1999, 21, 387-396. [CrossRef]

43. Brown, D.F.; Moerenhout, R.G. The pain experience and psychological adjustment to orthodontic treatment of preadolescents, adolescents, and adults. Am. J. Orthod. Dentofac. Orthop. 1991, 100, 349-356. [CrossRef]

44. Chow, J.; Cioffi, I. Pain and orthodontic patient compliance: A clinical perspective. Semin. Orthod. 2018, 24, 242-247. [CrossRef]

45. Erdinç, A.; Dinçer, B. Perception of pain during orthodontic treatment with fixed appliances. Eur. J. Orthod. 2004, 26, 79-85. [CrossRef] [PubMed]

46. Sandhu, S.S.; Sandhu, J. Orthodontic pain: An interaction between age and sex in early and middle adolescence. Angle Orthod. 2013, 83, 966-972. [CrossRef] [PubMed]

47. Alhaija, E.S.A.; AlDaikki, A.; Al-Omairi, M.K.; Al-Khateeb, S.N. The relationship between personality traits, pain perception and attitude toward orthodontic treatment. Angle Orthod. 2010, 80, 1141-1149. [CrossRef]

(C) 2020 by the authors. Licensee MDPI, Basel, Switzerland. This article is an open access article distributed under the terms and conditions of the Creative Commons Attribution (CC BY) license (http://creativecommons.org/licenses/by/4.0/). 